\title{
SOCIOLOGICAL STUDY RESULTS OF SELF-ASSESSMENT POSSIBILITIES FOR SELF-REALIZATION AMONG DOCTORS OF GENERAL PRACTICE - FAMILY MEDICINE IN UKRAINE
}

DOI: $10.36740 /$ WLek202003108

\author{
Larysa F. Matiukha, Nataliia V. Medvedovska, Tetiana M. Bukhanovska , Inna Yu. Dikhtiarenko \\ SHUPYK NATIONAL MEDICAL ACADEMY OF POSTGRADUATE EDUCATION, KYIV, UKRAINE
}

\begin{abstract}
The aim:To study self-assessment opportunities for primary care doctors' self-realization and their satisfaction with work during health care transformations in Ukraine. Materials and methods:To achieve this purpose, we compiled a questionnaire according to which an anonymous survey was conducted among 247 family doctors from six regions of Ukraine (Cherkasy, Zakarpattia, Odessa, Kirovohrad, Sumy, Kiev regions). In the study, we used the following research methods: sociological and medical-statistical. The method of mathematical statistics by applying Microsoft Excel 2013 was used to analyze research outcomes.

Results:The obtained data on self-assessment opportunities for primary care doctors' self-realization show that most of the respondents are not satisfied with their work. At the same time, the older general practitioners - family doctors are, the less important self-realization becomes for them, due to a disturbing fact of a highly probable lack of job, which is the first priority problem they may face. The willingness to work abroad is reported more than twice as high among family doctors aged up to 47 years. According to family doctors, irrespective of their age, the priority problems to be solved were reported as follows: poor financings; insufficient material and technical resources of out-patient clinics of the general medical practice; the necessity of returning national clinical protocols; the incompetence of health management; not clearly established interconnection between different levels of health care system.

Conclusions:Family doctors in Ukraine have mostly unsatisfactory conditions for their self-realization. This fact has a significant influence on their willingness to change a job, especially among doctors of young age.
\end{abstract}

KEY WORDS: family doctor, self-realization, sociological research

Wiad Lek. 2020;73(3):454-456

\section{INTRODUCTION}

The health of the population is determined on a state level as one of the highest values. Health care sector in Ukraine, mainly state-funded, is designed to provide available, high-quality, effective, timely, free medical care to each citizen. The affordability of health care, which has always been a national policy priority, is first of all realized through rendering primary medical care. The experience of the developed countries in the world demonstrates the proven economical and medical efficiency of primary medical care development based on the family medicine principles [1-5].

The international Health 2020 Strategy, which Ukraine also joined, determined effective vectors for noninfectious diseases prevention (causing $86.0 \%$ of death in the world) and factors of healthy lifestyle formation, health preservation and promotion for the population of all ages taking into account their regional features.

The family medicine is acknowledged to be a health reform priority in Ukraine, however, the development and strengthening of primary care staffing remains an unresolved strategic problem at the state level.

\section{THE AIM}

To study self-assessment opportunities for primary care doctors' self-realization and their satisfaction with work during health care transformations in Ukraine. To find out the willingness of primary care doctors to participate in reforms, their workplace satisfaction, the availability of opportunities for self-realization and (or) their willingness to change a job or even the country (to go abroad).

\section{MATERIALS AND METHODS}

To achieve the purpose of our study, we compiled a questionnaire which included six groups of questions regarding gender and age characteristics of respondents; places of their medical practice (city / village); opportunities for professional self-realization, the determination of their job importance among other priorities; their workplace satisfaction including the organization of work at the family medicine out-patient clinic; their willingness to change a job, or even the country to practice medicine (to go abroad); proposals for further primary care reforming in Ukraine.

The anonymous survey was conducted among 247 family doctors from 6 regions of Ukraine (Cherkasy, Zakarpattia, Odessa, Kirovohrad, Sumy, Kiev regions). The average age of respondents was $47,0 \pm 0,9$ years. In the study there were used sociological and medical-statistical research methods. 
The method of mathematical statistics by applying Microsoft Excel 2013 was used to analyze research outcomes.

\section{RESULTS}

The acknowledgement of primary health care based on the general medical practice principles to be a Ukrainian health care priority demands scientific maintenance for its introducing into practice. The obtained research data allowed us to state problems which have potentially negative impact on the organization of rendering primary medical care to the population. Among them, the most important is a problem of insufficient primary care staffing without clear state strategy for its planning, which can be explained by a low motivation of primary care doctors to work effectively, their unwillingness of self-realization due to the government-related uncertainty in organizing their work.

Among the interviewed family doctors (247 respondents), who are members of the public organization "The Ukrainian Association of Family Doctors" from six regions of Ukraine (Cherkasy, Zakarpattia, Odessa, Kirovohrad, Sumy, Kiev regions), family doctors from Sumy $(33,2 \pm$ $3,0 \%)$ and Zakarpattia $(21,1 \pm 2,6 \%)$ regions occurred to be the most active. An average age of respondents was 47,0 $\pm 0,9$ years, including the youngest age of 23 and the oldest age of 72 . The majority of the interviewed were family doctors having medical practice in the cities $(59,8 \pm 3,1 \%)$.

The obtained sociological data on family doctors' self-assessment of their possibilities for self-realization show that majority of respondents reported the work availability as more important factor $(86,0 \pm 2,2 \%$, at the maximum of $100,0 \%$ of respondents from Odessa, Kirovohrad, Kiev regions and the minimum of $67,3 \pm 6,5 \%$ in Zakarpattia region) if compared to the possibility of professional self-realization $(64,1 \pm 3,1 \%$, rating from $93,8 \pm 4,3 \%$ among respondents from Kirovohrad region up to $9,1 \%$ $\pm 8,7 \%$ of them from Kiev region).

According to the age distribution, the respondents of over 47 age group reported the lowest willingness for self-realization if compared to those who were younger $(61,6 \pm 4,4 \%$ against $80,3 \pm 3,6 \%$ among doctors aged up to 47 years).

The analysis of respondents' answers to questions about their work satisfaction showed no significant difference in age groups, every second family doctor is not satisfied with their work $(48,4 \pm 4,5 \%$ in the age group of up to 47 and $49,6 \pm 4,5 \%$ in the age group of over 47 ).

According to the regional distribution, it should be noted that a higher number of family doctors being satisfied with their work is from Kirovohrad $(75,0 \pm 7,7 \%)$ and Cherkasy $(69,2 \pm 7,4 \%)$ regions and the lowest number of them is from Sumy $(17,1 \pm 4,2 \%)$ and $\operatorname{Kiev}(18,2 \pm 11,6 \%)$ regions.

Under the existing circumstances in Ukraine, practically every third primary care doctor in Cherkasy $(28,2 \pm 7,2 \%)$, Odessa (25,8 $\pm 7,9 \%)$, Kirovohrad (28,1 $\pm 7,9 \%), \operatorname{Kiev}(36,4$ $\pm 14,5 \%)$, Sumy $(41,5 \pm 5,4 \%)$ and fewer respondents from Zakarpattia $(19,2 \pm 5,5 \%)$ regions are willing to change even the country of medical practice (to work abroad). The willingness to change the workplace and work abroad is twice higher among family doctors aged up to $47(41,0 \pm$ $4,5 \%$ against $20,8 \pm 3,6 \%$ in other age group). At the same time, $79.23 .6 \%$ of family doctors from the age group older than 47 years have no desire to work abroad.

Among the available medical care problems and their solutions during the difficult period of health care transformations in Ukraine, the highest number of respondents, irrespective of their age, reported as follows: uncertain and dramatic changes of organizational, economic and social conditions for citizens of Ukraine and the persons living on its territory, the insufficient primary medical care; poor financial support, in particular financial rationality and reasonable funds distribution; insufficient material and technical resources of out-patient clinics of the general medical practice; the necessity of returning national clinical protocols; incompetence of health care management; a lack of constructive compliance between health care levels; the insufficient legal protection of primary health care workers, and so forth.

\section{DISCUSSION}

The aim of studying self-assessment opportunities for primary care doctors' self-realization and their satisfaction with work during health care transformations in Ukraine was achieved. For the first time, the above mentioned survey among doctors of general practice - family medicine was conducted in Ukraine.

The revealed problems are stated to be highly relevant. The primary medical care doctors should be provided with good working conditions and the proper life level support to be able to render efficient primary medical care for the population as in $80.0 \%$ of requests. The primary care human resources component has been found out to be one of the main weak points of the health care system in Ukraine.

At the stage of modern health care sector reforming which began with the primary medical care level it is important to publish the obtained results, which will foster the fastest problem solutions. The policy of preserving young primary health care workforce and creating dignified working condition for it should be prioritized in Ukraine. The specificity of medical work demands continuing professional development and self-education which is significant for doctors to render efficient health care. The highly responsible profession of a doctor who provides efficient medical care to a patient is the key factor to be taken for granted in the health care comprehensive plans and investments to support proper working conditions for family doctors.

\section{CONCLUSIONS}

Thus, the development of primary health care remains the priority in Ukraine in spite of the fact that during the period of reforming its vectors have been changed to a certain extend. Planning the primary health care workforce and the quality of health workers' services should be supported by valid data and knowledge, taking into account the best 
international and national practices and the Global Strategy on Human Resources for Health.

Modern conditions demand further work on creating legislative standards for functioning and further development of primary health care in Ukraine, which includes the government strategy for strengthening primary care human resources to avoid risks of loss of the young qualified health professionals.

\section{REFERENCES}

1. Fernholm R., Holzmann M., Malm-Willadsen K. et al. Patient and provider perspectives on reducing risk of harm in primary health care: a qualitative questionnaire study in Sweden. Scand J Prim Health Care. 2020; 24:1-9. doi: 10.1080/02813432.2020.1717095.

2. Ginsburg G.S., Wu R.R., Orlando L.A. Family health history: underused for actionable risk assessment. Lancet. 2019; 394(10198):596-603. doi: 10.1016/S0140-6736(19)31275-9.

3. Ramond-Roquin A., Chouinard MC., Diallo BB. et al. Chronic disease prevention and management programs in primary care: Realist synthesis of 6 programs in Quebec. Can Fam Physician. 2019;65(8):559-566.

4. Senior H., Grant M., Rhee JJ. et al. General practice physicians' and nurses' self-reported multidisciplinary end-of-life care: a systematic review. BMJ Support Palliat Care. 2019 Aug 29. pii: bmjspcare-2019-001852. doi: 10.1136/bmjspcare-2019-001852.

5. Fisher S.J., Margerison L.N., Jonker L. Development and cohort study of an audit approach to evaluate patient management in family practice in the UK: the $7 S$ tool. Fam Pract. 2019 Sep 16. pii: cmz053. doi: 10.1093/ fampra/cmz053.
The article is a fragment of the scientific research work "Scientific substantiation of modern approaches to optimization of preventive directions at the primary level of providing medical care" (deadline-2018-2022, state registration number 0113U002455).

\section{ORCID and contributionship:}

Larisa F. Matiukha - 0000-0001-8249-8583 A,E,F

Nataliia V. Medvedovska - 0000-0003-3061-6079 D,F

Tetiana N. Bukhanovska - 0000-0001-6347-5554 ${ }^{B, C, D, F}$

Inna Yu. Dikhtiarenko - ${ }^{B, C, F}$

\section{Conflict of interest:}

The Authors declare no Conflict of interest.

\section{CORRESPONDING AUTHOR Tetiana M. Bukhanovska}

Saksaganskogo str, 100, Kyiv, 01032, Ukraine

tel: +38050941386

tatiana.malceva@gmail.com

Received: 17.01 .2020

Accepted: 05.03 .2020

A - Work concept and design, B - Data collection and analysis, C - Responsibility for statistical analysis, D-Writing the article, $\mathbf{E}$-Critical review, $\mathbf{F}$ - Final approval of the article 